\title{
Weight-based dosing of lenvatinib for advanced hepatocellular carcinoma
}

\author{
Sadahisa Ogasawara ${ }^{1,2}$, Yoshihiko Ooka ${ }^{1}$, Naoya Kato ${ }^{1,2}$ \\ ${ }^{1}$ Department of Gastroenterology, Graduate School of Medicine, Chiba University, Chiba, Japan; ${ }^{2}$ Translational Research and Development Center, \\ Chiba University Hospital, Chiba, Japan \\ Correspondence to: Sadahisa Ogasawara, MD, PhD. Department of Gastroenterology, Graduate School of Medicine, Chiba University, 1-8-1 Inohana, \\ Chuo-ku, Chiba 260-8670, Japan. Email: ogasawaras@chiba-u.jp. \\ Provenance and Peer Review: This article was commissioned by the Editorial Office, Hepatobiliary Surgery and Nutrition. The article did not undergo \\ external peer review.
}

Submitted Aug 07, 2019. Accepted for publication Sep 27, 2019.

doi: 10.21037/hbsn.2019.09.21

View this article at: http://dx.doi.org/10.21037/hbsn.2019.09.21

Lenvatinib is an oral molecular target agent that blocks vascular endothelial growth factor receptors $1-3$, fibroblast growth factor receptors $1-4$, platelet-derived growth factor receptor $\alpha, R E T$, and KIT. It is noninferior, but not statistically superior, to sorafenib with regard to overall survival, according to the findings of a phase 3 trial of lenvatinib versus sorafenib as first-line therapy for advanced hepatocellular carcinoma (HCC) (the REFLECT trial) (1). Nowadays, lenvatinib has been approved all over the world and has become the second front-line tyrosine kinase inhibitor in patients with advanced HCC. The recommendations for starting lenvatinib therapy for advanced HCC are different from those for other molecular target agents in patient with advanced HCC in that dose is based on body weight ( $\geq 60 \mathrm{~kg}: 12 \mathrm{mg}$ once daily; $<60 \mathrm{~kg}: 8 \mathrm{mg}$ once daily). The aim of this article is to discuss the weight-based dosing of lenvatinib for advanced HCC.

Lenvatinib was developed for the treatment of radioiodine-refractory differentiated thyroid cancer before its use in treating advanced HCC was considered. The initial dose of lenvatinib for thyroid cancer was defined as $24 \mathrm{mg}$ once daily (2). HCC occurs predominantly in patients with underlying chronic liver disease and cirrhosis. When lenvatinib was developed for use in patients with advanced HCC, the starting dose was reevaluated according to recommendations (3). In phase 1 of the REFLECT study, which focused on HCC, 20 patients (9 with ChildPugh class A disease and 11 with Child-Pugh class B disease) were enrolled (4). The maximum tolerable dose for patients with Child-Pugh A and B class advanced HCC was reported to be 12 and $8 \mathrm{mg}$ once daily, respectively. This recommended dosage was used in a single-arm, openlabel, multicenter phase 2 study (5). In Japan and Korea,
46 patients with advanced HCC who did not qualify for surgical resection or local therapies were enrolled this study and received lenvatinib at a dosage of $12 \mathrm{mg}$ once daily. The median time before the disease began to progress again was 7.4 months, and the objective response rate was $37 \%$.

Because of adverse events, the dosage had to be modified for $74 \%$ of the patients, and $22 \%$ had to discontinue the drug. The patients who required dose modification or had to discontinue treatment within 30 days had a lower median body weight $(54.1 \mathrm{~kg})$ than did patients who did not required regimen change $(67.9 \mathrm{~kg})$. Moreover, in this study, pre-dosing blood samples were obtained for pharmacokinetic assessments on days 1, 8, 15, and 22 of cycle 1 and on day 1 of cycles 2 and 3. The median trough concentrations on day 15 of cycle 1 in patients who required dose modifications and in those who did not were 62.4 and $33.0 \mathrm{ng} / \mathrm{mL}$, respectively.

Before a phase 3 study, an additional optimal dose assessment study for patients with Child-Pugh class A advanced HCC was conducted with pooled data from the phase 2 study (6). This population pharmacokinetic analysis confirmed the exposure-response relationship with regard to safety and efficacy in patients with advanced HCC who received lenvatinib, $12 \mathrm{mg}$ once daily. The results of this study showed a strong exposure-response relationship, between high area under the curve (AUC) for lenvatinib and low body weight (best cutoff values for lenvatinib AUC and body weight were $2,430 \mathrm{ng} / \mathrm{mL}$ and $57.8 \mathrm{~kg}$, respectively). This relationship could be used to predict which patients were likely to need dose modification or treatment discontinuation. According to these findings, the recommended starting doses for patients weighing $60 \mathrm{~kg}$ or more and those weighing less than $60 \mathrm{~kg}$ were 12 and $8 \mathrm{mg}$, respectively. 
The REFLECT trial was the international, multicenter, randomized, open-label study conducted with 954 patients who had previously untreated, metastatic, or unresectable HCC. Patients were randomly assigned, in a 1:1 ratio, to receive either lenvatinib (12 $\mathrm{mg}$ orally once daily for patients with a baseline body weight of $60 \mathrm{~kg}$ or more and $8 \mathrm{mg}$ orally once daily for patients with a baseline body weight of less than $60 \mathrm{~kg}$ ) or sorafenib (400 mg orally twice daily, regardless of weight). Treatment continued either until disease progression was confirmed radiologically or if toxic effects were unacceptable. Subgroup analyses in the REFLECT trial indicated that the overall lengths of survival of patients receiving lenvatinib who weighed $60 \mathrm{~kg}$ or more and those who weighed less than $60 \mathrm{~kg}$ were 13.4 and 13.7 months, respectively; for patients weighing $60 \mathrm{~kg}$ or more, the hazard ratio (HR, in contrast to sorafenib) was 0.85 [95\% confidence interval (CI), 0.65 to 1.11 ], and for those weighing less than $60 \mathrm{~kg}, \mathrm{HR}=0.95$ (95\% CI, 0.79 to 1.14) (7). Moreover, in the two groups of patients with different weights, the mean dose intensities of lenvatinib and rates of occurrence of common adverse events (hypertension, diarrhea, decreased appetite, weight loss, and fatigue) were similar. These data confirmed that basing the starting dosage of lenvatinib on weight was reasonable for patients with advanced HCC.

In conclusion, these findings might strongly contribute to the success of a phase 3 trial. A weight-based dosing approach should be followed when lenvatinib is used for advanced HCC in patients with Child-Pugh class A disease in real-world practice.

\section{Acknowledgments}

We would also like to thank Enago (www.enago.jp) for the English language review.

Funding: None.

\section{Footnote}

Conflicts of Interest: All authors have completed the ICMJE uniform disclosure form (available at https://hbsn.amegroups. com/article/view/10.21037/hbsn.2019.09.21/coif). SO received honoraria from Bayer, Eisai, Eli Lilly, consulting or advisory fees from Bayer, Eisai, Merck \& Co., Inc., Chugai Pharma, Eli Lilly, and research grants from Bayer and Eisai. YO received honoraria from Bayer, Eisai, and Sumitomo Dainippon Pharma. NK received honoraria from Bayer and Eisai, consulting or advisory role from Bayer and Eisai, research funding from Bayer and Eisai.
Ethical Statement: The authors are accountable for all aspects of the work in ensuring that questions related to the accuracy or integrity of any part of the work are appropriately investigated and resolved.

Open Access Statement: This is an Open Access article distributed in accordance with the Creative Commons Attribution-NonCommercial-NoDerivs 4.0 International License (CC BY-NC-ND 4.0), which permits the noncommercial replication and distribution of the article with the strict proviso that no changes or edits are made and the original work is properly cited (including links to both the formal publication through the relevant DOI and the license). See: https://creativecommons.org/licenses/by-nc$\mathrm{nd} / 4.0 /$.

\section{References}

1. Kudo M, Finn RS, Qin S, et al. Lenvatinib versus sorafenib in first-line treatment of patients with unresectable hepatocellular carcinoma: a randomised phase 3 noninferiority trial. Lancet 2018;391:1163-73.

2. Schlumberger $M$, Tahara $M$, Wirth LJ, et al. Lenvatinib versus placebo in radioiodine-refractory thyroid cancer. $\mathrm{N}$ Engl J Med 2015;372:621-30.

3. Llovet JM, Di Bisceglie AM, Bruix J, et al. Design and endpoints of clinical trials in hepatocellular carcinoma. J Natl Cancer Inst 2008;100:698-711.

4. Ikeda M, Okusaka T, Mitsunaga S, et al. Safety and Pharmacokinetics of Lenvatinib in Patients with Advanced Hepatocellular Carcinoma. Clin Cancer Res 2016;22:1385-94.

5. Ikeda K, Kudo M, Kawazoe S, et al. Phase 2 study of lenvatinib in patients with advanced hepatocellular carcinoma. J Gastroenterol 2017;52:512-9.

6. Tamai T, Hayato S, Hojo S, et al. Dose Finding of Lenvatinib in Subjects With Advanced Hepatocellular Carcinoma Based on Population Pharmacokinetic and Exposure-Response Analyses. J Clin Pharmacol 2017;57:1138-47.

7. Okusaka T, Ikeda K, Kudo M, et al. Safety and efficacy of lenvatinib by starting dose ( $8 \mathrm{mg}$ or $12 \mathrm{mg}$ ) based on body weight in patients with unresectable hepatocellular carcinoma in REFLECT. J Clin Oncol 2019;37:316.

Cite this article as: Ogasawara S, Ooka Y, Kato N. Weightbased dosing of lenvatinib for advanced hepatocellular carcinoma. HepatoBiliary Surg Nutr 2020;9(2):253-254. doi: 10.21037/hbsn.2019.09.21 